\title{
Alexandre Dumas, Le Sphinx rouge
}

\section{Lise Sabourin}

\section{OpenEdition}

\section{Journals}

\section{Édition électronique}

URL : https://journals.openedition.org/studifrancesi/21456

DOI : 10.4000/studifrancesi.21456

ISSN : 2427-5856

\section{Éditeur}

Rosenberg \& Sellier

\section{Édition imprimée}

Date de publication : 1 décembre 2019

Pagination : 590-591

ISSN : 0039-2944

\section{Référence électronique}

Lise Sabourin, «Alexandre Dumas, Le Sphinx rouge », Studi Francesi [En ligne], 189 (LXIII | III) | 2019, mis en ligne le 01 mars 2020, consulté le 11 novembre 2021. URL : http://journals.openedition.org/ studifrancesi/21456 ; DOI : https://doi.org/10.4000/studifrancesi.21456

\section{Ce document a été généré automatiquement le 11 novembre 2021.}

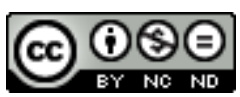

Studi Francesi è distribuita con Licenza Creative Commons Attribuzione - Non commerciale - Non opere derivate 4.0 Internazionale. 


\section{Alexandre Dumas, Le Sphinx rouge}

Lise Sabourin 


\section{RÉFÉRENCE}

Alexandre Dumas, Le Sphinx rouge, établissement du texte, préface, notes, dictionnaire des personnages par R. Portocala, suivi de La Colombe, Paris, Cherche-Midi, 2018, 713 pp.

1 Radu Portocala délivre, à partir de la parution dans le journal "Les Nouvelles" du 17 octobre 1865 au 23 mars 1866, l'édition complète de ce roman historique écrit à la demande de Jules Noriac par un Alexandre Dumas qui, vingt ans après la rédaction de ses Mousquetaires, en écrit ainsi la suite immédiate.

2 Le personnage du comte de Moret, bâtard reconnu d'Henri IV, est suffisamment mineur dans l'histoire comme dans cette fiction pour que la première édition en livre, incomplète (3 parties sur 4), aux Éditions universelles en 1946, ait préféré au titre éponyme initial celui du Sphinx rouge, ici repris, tant l'intérêt dumasien se porte sur ce ministre tout-puissant dont il admire le talent de pouvoir mis au service de la grandeur française.

3 Le manuscrit que l'éditeur y confronte avait été donné au prince Narischkine, dédicataire du roman, lors du voyage en Russie de Dumas. Loin de donner la première place aux exploits chevaleresques, il sonde ici, dans la lignée des Historiettes de Tallemant des Réaux ou des Mémoires de Bassompierre, les caractères et les mécanismes de l'histoire politique, finissant par réhabiliter le roi Louis XIII.

4 L'éditeur a ajouté comme une «suite anticipée» La Colombe, récit rédigé en 1850, qui imagine la survie du comte de Moret (tué à la bataille de Castelnaudary le $1^{\text {er }}$ septembre 1632, son corps ne fut jamais retrouvé) mué en un pieux frère Jean-Baptiste qui échange en 1638 des lettres avec son amour de jeunesse Isabelle de Lautrec.

5 Grâce à ce volume des éditions du Cherche-Midi réapparaît donc pour le grand public un roman oublié des dernières années de Dumas, où il n'a rien perdu de sa verve et de son allant en cette fiction égrenée dans le journal qu'il allait racheter et titrer "Le Mousquetaire" en novembre 1866. 